\title{
Solar Powered Wireless Intrusion Detection System in Agricultural Farms
}

\author{
Rohan Paranjpe \\ Information Technology \\ Xavier Institute of Engineering \\ Bombay
}

\author{
Hiralal Purohit \\ Information Technology \\ Xavier Institute of Engineering \\ Bombay
}

\author{
Rohan Joshi \\ Information Technology \\ Xavier Institute of Engineering \\ Bombay
}

\begin{abstract}
In recent times we observe that farmers are committing suicide because they cannot cope up with the physical, mental, financial and various factors that push them over the edge. One such factor is the constant encroachment by animals on farmlands thereby incurring an irreparable loss to the farmers. Often the fully grown crops get razed to the ground when animals intrude into the farmland. This problem is rising at an alarming rate as due to deforestation the animals living in the region wander off in the human territory. To prevent such mishaps, farmers need to be on their guard when crops are almost ready to be harvested. Farmers have to guard their agricultural lands throughout the chilly weather or unforgiving heat at night. Guarduino is an intelligent animal farm intrusion detection system which is based on IoT using basic components like Arduino Mega, Proximity Sensor, LED, Buzzer, WiFi Module, LCD. It solves this burdensome problem as it's cheap, power efficient, eco-friendly, reduces manual labor of the farmer, reduces the overall loss incurred to the farmer by a decent margin hence giving him a peace of mind. Guarduino also detects the precise location of the intrusion and acts as a surveillance system. There will be LED light stream at the fence which will make the animal aware of some presence in the area and temporarily causing a stun so as to just scare the animal away from the plantation. WiFi module has enabled us to gather intrusion data on the cloud. To prevent such mishaps, farmers need to be on their guard when crops are almost ready to be harvested.If such an intrusion is detected quickly by the use of IOT, the farmer need not have his physical presence to detect an intrusion but will be able to respond quickly if such a thing happens.
\end{abstract}

\section{Keywords}

Wireless, IoT, Sensors, Agricultural Farm, ArduinoMega 2560, Animal, Solar, Intrusion, Crops, Surveillance.

\section{INTRODUCTION}

The Internet of Things (IoT) is the community of physical devices, cars, home appliances, and different gadgets embedded with electronics, software, sensors, actuators, and connectivity which allows these things to attach and exchange facts, creating possibilities for more direct integration of the bodily global into computer-primarily based systems, resulting in performance enhancements, monetary advantages, and reduced human hard work. A complete IoT system integrates 4 awesome components: sensors/gadgets, connectivity, information processing, and a consumer interface.

\section{REVIEW OF LITERATURE}

Farmlands and plantations in India are usually very large in size and can run into hundreds of acres. Constructing fences along these large expanses of land is prohibitively expensive and sometimes ineffective as intruders can easily jump over them and disrupt the farm and possibly the whole cultivation especially when such fences go round dark and remote locations. This work proposes the use of an IoT based intrusion detection system that uses active sensors to detect the presence of intruders and logs such intrusions for monitoring purposes [1]. With these logged information owners of such farmlands can know precisely when and where to deploy or intensify security activities around these large farmlands or plantations. In this project, we describe a virtual fence made from a motion sensor integrated with a microcontroller and deployed around specific locations. Logged data and results from monitored experiments conducted with the virtual fence are then presented Detecting Intrusion in Large Farm Lands [3].

Each sensor module was mounted inconspicuously at the edge of the area of interest [6]. Once a person moves across its field of view, the sensor detects the passage and sends a "HIGH" signal to the micro controller. This, in turn, updates the data on thingspeak.com and also sends message to the client's mobile [5]. For this we have to execute a stream of AT commands for testing the connection manually using the Serial monitor of Arduino. If the results are satisfactory then we can proceed with our implementation wherein the string of AT commands get executed within the program itself [2]. 


\section{BLOCK DIAGRAMS}

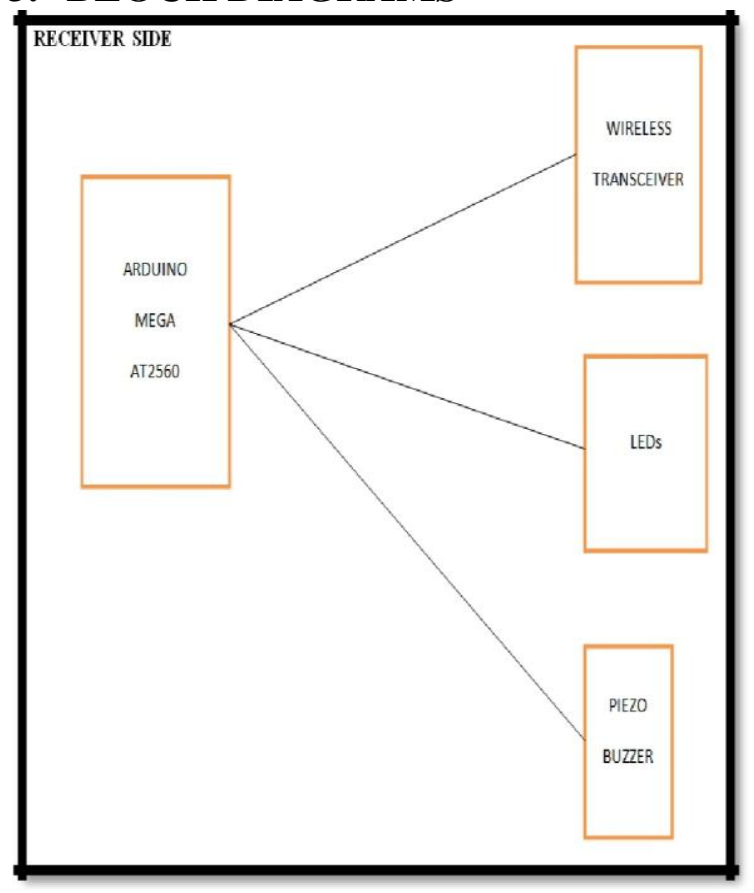

Figure 1: Block Diagram for Receiver

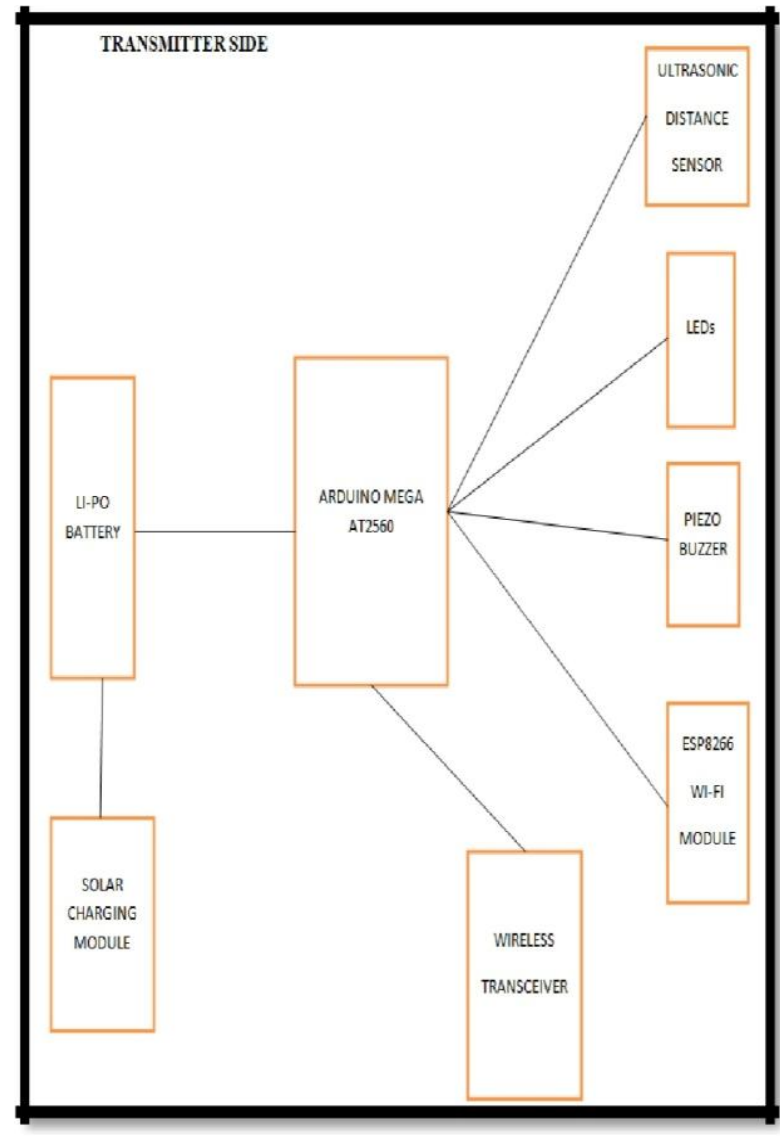

Figure 2 :- Block Diagram for Transmitter / Sender

\section{HARDWARE REQUIREMENTS}

- Arduino Mega 2560

- Ultrasonic Distance sensor

- $\quad$ LED \& Resistors

- Buzzer

- $\quad$ SP8266 WiFi Module

- Wireless transceiver

- Power bank or Li-Po Batttery set

- Solar Panel with module

\section{SOFTWARE REQUIREMENTS}

- Windows XP/Vista/7/8/10 or Linux or MacOS

- 2 GB RAM with i3 Processor

- Arduino IDE (For Programming)

- $\quad$ USB Port (For Power Connection)

\section{CLOUD PLATFORM}

ThingSpeak $^{\mathrm{TM}}$ is an IoT analytics platform service from MathWorks ${ }^{\circledR}$, the makers of MATLAB ${ }^{\circledR}$ and Simulink ${ }^{\circledR}$. ThingSpeak allows you to aggregate, visualize, and analyze live data streams in the cloud. ThingSpeak accelerates the development of proof-of-concept IoT systems, especially those that require analytics. You can build IoT systems without setting up servers or developing web software. For small- to medium-sized IoT systems, ThingSpeak provides a hosted solution that can be used in production. Using IFTTT (If This Then That) we have implemented and SMS service for alerting the farmer with minimum delay between actual intrusion and intimation to the farmer.

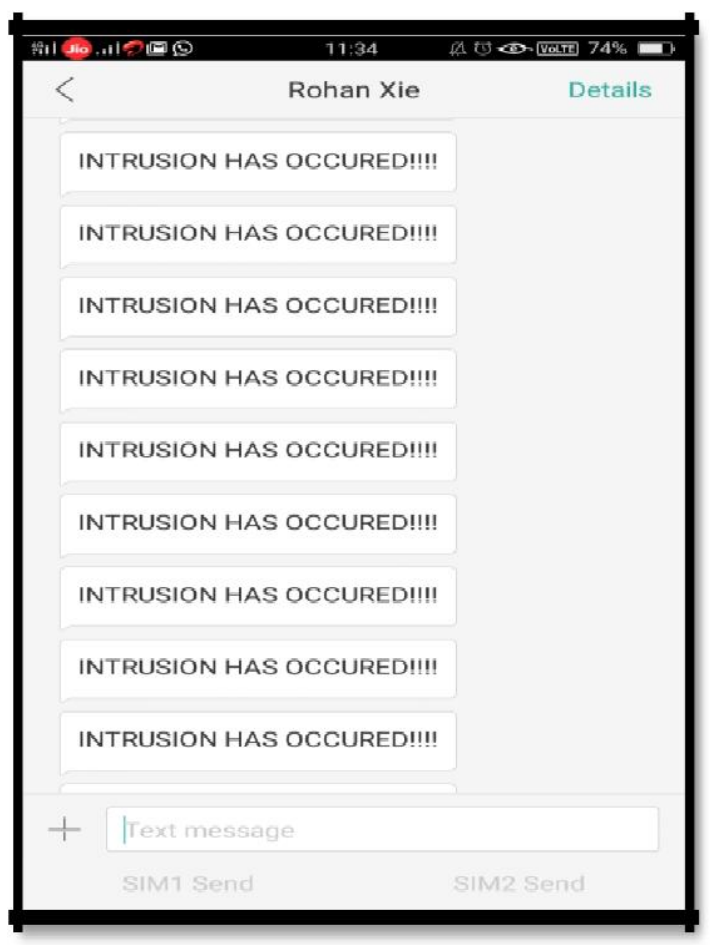

Figure 3:- SMS sent to alert the Farmer 


\section{IMPLEMENTATION METHODOLOGY}

Whenever, there is an intrusion the ultrasonic distance sensor will sound the alarm using a buzzer and stream of LED lights at the actual place of intrusion as well as alert the farmer. This will scare off the animals, animals and will give some time for the farmer to react.

-

There are villages where there is no mobile network or any internet connection. Wireless Transceiver works on frequency band from $433.4 \mathrm{MHz}$ to $473.0 \mathrm{MHz}$. So, there is no need of any network or internet connection.

- The range of this Wireless Tranciever is $1.8 \mathrm{~km}$ which is more than sufficient to cover the area of the field.

-

For the farmers who own areas more than the coverage area of Wireless Tranciever, multiple Wireless Trancievers can be used for routing the original signal.

-

Data in all forms (Graphs) can be used to form a pattern and using Machine Learning we can predict when a probable intrusion can happen in the future.

The use of Solar Cells is used along with electrical batteries so that the cost of maintenance decreases to a minimum amount and will turn out to be EcoFriendly.

\section{RESULTS AND CONCLUSION}

IoT based intrusion detection system is designed using Arduino Mega 2560, ultrasonic distance sensor, ESP $8266 \mathrm{WiFi}$ module, Wireless Transceiver. The project, when implemented will totally eliminate the need for the farmer to patrol the farmland in unforgiving weather conditions. This system will help reduce the physical and mental stress levels of the farmer. There are solutions available in the market but they are pretty expensive hence the common farmer cannot bear expenses which may, in turn, become a liability for them.

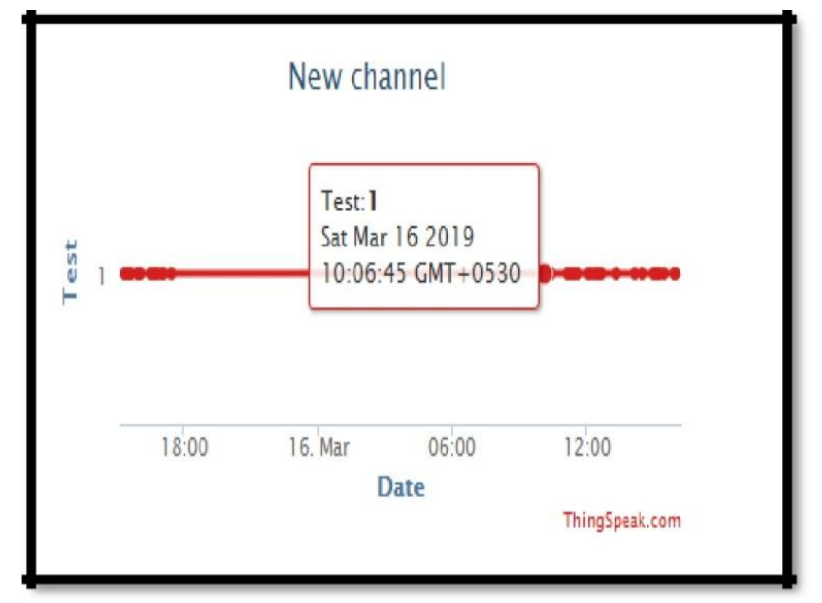

Figure 4: Detected Intrusions in the form of Graph

\begin{tabular}{|r|l|l|}
\hline 1 & created_at & entry_id \\
\hline 2 & $2019-03-14$ 14:18:18 UTC & \\
\hline 3 & $2019-03-14$ 14:18:50 UTC & \\
\hline 4 & $2019-03-1414: 21: 18$ UTC & \\
\hline 5 & $2019-03-14$ 14:23:41 UTC & \\
\hline 6 & $2019-03-1414: 28: 44$ UTC & \\
\hline 7 & $2019-03-1414: 33: 23$ UTC & \\
\hline 8 & $2019-03-1416: 01: 19$ UTC & \\
\hline 9 & $2019-03-1416: 02: 04$ UTC & \\
\hline 10 & $2019-03-14$ 16:02:29 UTC & \\
\hline 11 & $2019-03-1416: 05: 06$ UTC & \\
\hline 12 & $2019-03-14$ 16:05:29 UTC & \\
\hline 13 & $2019-03-1416: 19: 14$ UTC & \\
\hline 14 & $2019-03-1416: 25: 50$ UTC & \\
\hline 15 & $2019-03-15$ 06:43:11 UTC & \\
\hline 16 & $2019-03-1506: 43: 52$ UTC & \\
\hline 17 & $2019-03-15$ 06:44:56 UTC & \\
\hline 18 & $2019-03-1506: 48: 42$ UTC & \\
\hline 19 & $2019-03-15$ 06:49:54 UTC & \\
\hline 20 & $2019-03-1506: 52: 19$ UTC & \\
\hline & & \\
\hline
\end{tabular}

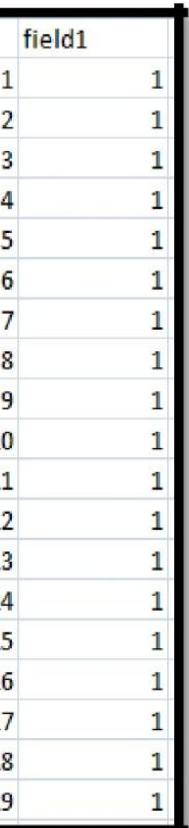

\section{REFERENCES}

[1] A Prototype for Agricultural Intrusion Detection using Wireless Sensor Link:https://ieeexplore.iee.org/document/7249452 .

[2] www.arduino.cc accessed on $07^{\text {th }}$ September 2018 at $11 ; 15 \mathrm{AM}$

[3] www.vedblogs.wordpress.com accessed on $25^{\text {th }}$ November 2018 at 8:45 PM.

[4] www.instructables.com accessed on $18^{\text {th }}$ October 2018 at $4: 15 \mathrm{PM}$.

[5] www.electronicshub.com accessed on $26^{\text {th }}$ September 2018 at 12:56 PM.

[6] https://www.allaboutcircuits.com accessed on $13^{\text {th }}$ January 2019 at 11:20 AM.

[7] www.howtomechatronics.com accessed on $12^{\text {th }}$ November 2018 at 3:13 